\title{
Componentes do rendimento de grãos em trigo e seus efeitos diretos e indiretos na produtividade ${ }^{1}$
}

\author{
Fernando Vesohoski ${ }^{2}$, Volmir Sergio Marchioro ${ }^{3 *}$, Francisco de Assis Franco $^{4}$, Alexandro Cantelle ${ }^{5}$
}

\section{RESUMO}

Com o uso da análise de trilha, é possível avaliar as associações entre caracteres e desdobrar a correlação existente em efeitos diretos e indiretos. O objetivo deste estudo foi estimar correlações genotípicas e desdobrar os efeitos diretos e indiretos dos componentes do rendimento de grãos sobre a produtividade de cultivares de trigo. O experimento foi conduzido no ano de 2008, no campo experimental da Cooperativa Central de Pesquisa Agrícola (Coodetec) no município de Palotina/PR. O delineamento experimental utilizado foi de blocos casualizados com três repetições. As características avaliadas foram: tamanho da espiga, número de espiguetas por espiga, número de grãos por espiga, número de espigas por metro, massa de mil grãos e rendimento de grãos. Os resultados obtidos foram submetidos à análise de variância e à análise de trilha. A análise de variância mostrou diferença entre os genótipos avaliados, indicando a presença de variabilidade genética para os caracteres avaliados. A seleção indireta, por meio do número de grãos por espiga, levando em consideração a massa de mil grãos, é a melhor estratégia para a obtenção de genótipos superiores em rendimento de grãos.

Palavras-chave: Triticum aestivum L., análise de trilha, seleção indireta.

\section{ABSTRACT}

\section{Components of grain yield in wheat and its direct and indirect effects on productivity}

Using path analysis it is possible to evaluate the relationships between characters and decompose the correlation into direct and indirect effects. The objective of this study was to estimate genotypic correlations and decompose the direct and indirect effects of yield components on grain yield of wheat cultivars. The experiment was conducted in 2008, in the experimental field of the Cooperativa Central de Pesquisa Agrícola (COODETEC) in Palotina, PR, Brazil. The experiment was arranged in a randomized block design, with three replications. The characteristics evaluated were: ear size, number of spikelets per spike, number of grains per spike, number of spikes per meter, thousand grain weight and grain yield. The results were subjected to analysis of variance and path analysis. The variance analysis showed differences between genotypes, indicating the presence of genetic variability for traits. Indirect selection via number of grains per spike, taking into account the thousand grain weight is the best strategy for obtaining superior genotypes in grain yield.

Key words: Direct selection, path analysis, Triticum aestivum L.

\footnotetext{
Recebido para publicação em março de 2010 e aprovado em março de 2011

${ }^{1}$ Trabalho de Conclusão de Curso, desenvolvido na Cooperativa Central de Pesquisa Agrícola, Cascavel, Paraná, Brasil

Engenheiro-Agrônomo. Cooperativa Central de Pesquisa Agrícola, BR 467- KM 98, Caixa Postal 301, 85.813-450, Cascavel/ PR, Brasil. fvesohoski@coodetec.com.br

${ }^{3}$ Engenheiro-Agrônomo, Dr.Cooperativa Central de Pesquisa Agrí́cola, BR 467- KM 98, Caixa Postal 301, 85.813-450, Cascavel/PR. volmir@marchioro.eng.br

${ }^{4}$ Engenheiro- Agrônomo, Dr. Cooperativa Central de Pesquisa Agrícola, BR 467- KM 98, Caixa Postal 301, 85.813-450, Cascavel/PR. franco@coodetec.com.br

${ }_{5}^{5}$ Acadêmico de Agronomia. Faculdade Assis Gurgacz. Avenida das Torres n. 500, 85.806-095, Bairro FAG, Cascavel/PR. alex_cantelle@hotmail.com
} 


\section{INTRODUÇÃO}

O centro de origem e domesticação do trigo situa-se das montanhas de Zagros (Irã - Iraque) até as montanhas Taurin, na Turquia, e, nas montanhas a sudoeste do mar Mediterrâneo (Feldman, 1976), sendo a espécie Triticum aestivum a mais cultivada no Brasil e no mundo. $\mathrm{O}$ trigo foi uma das primeiras culturas domesticadas e por 8000 anos tem sido a base da alimentação das principais civilizações da Europa, Ásia e África. A partir de sua domesticação, entre 7000 e 9000 a.C., este cereal passou por um processo de grande expansão por todo mundo (Bell, 1987).

Segundo Marchioro et al. (2009), as principais características almejadas para os novos cultivares de trigo são: rendimento de grãos; qualidade industrial; tolerância à germinação na espiga, à moléstias, à seca, ao alumínio tóxico do solo, à debulha natural e ao acamamento; capacidade de afilhamento; boa resposta à adubação e ampla adaptabilidade e estabilidade fenotípica. Entretanto, segundo Carvalho et al. (2008), uma das grandes limitações no melhoramento de plantas autógamas, como o trigo, é o tempo necessário para se atingir a homozigose após a hibridação, já que o procedimento para a obtenção destas linhagens com alta homozigose requer várias gerações de autofecundação, sem contar com os testes a que a nova linhagem terá que ser submetida até o seu lançamento como cultivar.

Quando a seleção no melhoramento genético é realizada com base em plantas individuais, os fatores relacionados com a ação gênica, com o efeito de ambiente e com a reduzida disponibilidade de sementes são fatores restritivos em gerações com elevada frequência de heterozigotos (Benin et al., 2005). Estes fatores, somados a heterogeneidade de ambientes, acabam apontando maior erro experimental. Nestas condições, procedimentos estatísticos que possibilitem a partição da variância fenotípica em componentes genotípicos, principalmente, em gerações de populações com elevada frequência de heterozigotos, são desejáveis. Em vista destes efeitos, a correlação fenotípica pode induzir o melhorista a estratégias pouco efetivas (Chaudaury, 1973). Assim, é importante distinguir as causas genéticas e de ambiente que, combinadas, resultem na correlação fenotípica (Almeida, 1988).

Procurando compreender melhor a associação entre caracteres, Wright (1921) propôs um método, denominado análise de trilha (path analysis), que desdobra as correlações estimadas em efeitos diretos e indiretos de cada caráter sobre uma variável básica, que segundo Cruz \& Regazzi (1997), é constituído pelo conhecimento prévio do pesquisador e de possíveis inter-relações expressas em diagramas de trilha. $\mathrm{O}$ sucesso dessa análise reside basicamente na formulação do relacionamento de causa e efeito entre os caracteres estudados (Silva et al., 2005).

Estudando as correlações de efeitos diretos e indiretos, Benin et al. (2003) encontraram que a inexpressiva concordância entre estimativas de associação simples e efeito direto não forneceram contribuição para a utilização de relações genéticas e fenotípicas na identificação de associações herdáveis de grande interesse. Porém, os efeitos diretos e indiretos mostraram que os caracteres peso de panícula, número de panículas por planta e peso médio dos grãos podem ser empregados com sucesso na seleção de plantas com alta produtividade de grãos em aveia.

Caierão et al. (2001) observaram também que a seleção indireta para o rendimento de grãos, quando se trata de peso de panícula, levando em consideração o número de grãos por panícula e,ou, a massa de grãos, é a melhor estratégia de seleção indireta para a escolha de genótipos superiores em aveia. Sendo que, em termos produtivos, genótipos com menor potencial de afilhamento estão sujeitos a maiores dependências de densidade de semeadura e esta característica está relacionada também com a senescência de afilhos (Valério et al., 2008).

Diante destas considerações, o presente trabalho teve como objetivo estimar as correlações genotípicas e o desdobramento dos efeitos diretos e indiretos dos componentes do rendimento de grãos em trigo sobre a produtividade em 12 cultivares.

\section{MATERIAL E MÉTODOS}

O experimento foi conduzido no ano agrícola de 2008, no campo experimental da Cooperativa Central de Pesquisa Agrícola (Coodetec) no município de Palotina, Paraná. O município possui clima temperado com precipitação pluviométrica média anual em torno de $1600 \mathrm{~mm}$, Latitude $24^{\circ} 18^{\prime} \mathrm{S}$ e Longitude $53^{\circ} 55^{\prime} \mathrm{W}$ e Altitude de 330 metros. O solo é da classe Nitossolo Vermelho eutroférrico, sem a presença de alumínio, apresentando textura argilosa e relevo semiondulado.

Antes da semeadura, foi realizada amostragem do solo para realização das análises químicas, sendo as amostras retiradas na profundidade de $0-20 \mathrm{~cm}$. Com base nos resultados da análise, procedeu-se a adubação de base com a aplicação de $300 \mathrm{~kg} \mathrm{ha}^{-1}$ de N- $\mathrm{P}_{2} \mathrm{O}_{5}-\mathrm{K}_{2} \mathrm{O}(8-20-20)$ e mais $60 \mathrm{~kg} \mathrm{ha}^{-1} \mathrm{de} \mathrm{N}$, aplicado em cobertura, no início do afilhamento.

Doze cultivares de trigo foram utilizados no experimento, conduzidos em ensaios de valor de cultivo e uso (VCU), sendo elas: CD 104, CD 105, CD 108, CD 113, CD 114, CD 116, CD 117, CD 118, CD 150, BRS 208, BRS 210, IPR 85. Todos os cultivares foram escolhidos com base na necessidade de informações das suas principais ca- 
racterísticas que contribuem para o rendimento de grãos. Todas as linhagens foram semeadas com densidade de 350 sementes aptas por metro quadrado. Antes da semeadura, as sementes foram tratadas com Triadimenol + Imidacloprid.

O delineamento experimental utilizado foi o de blocos ao acaso, com três repetições em parcelas constituídas de seis linhas de $5 \mathrm{~m}$ de comprimento, espaçadas em 0,20 $\mathrm{m}$ entre linhas, sendo a semeadura efetuada mecanicamente. A adubação e o controle de doenças e pragas foram efetuados conforme recomendações técnicas CSBPT (2006).

Os caracteres avaliados no experimento foram os seguintes: tamanho da espiga (TES), número de espiguetas por espiga (NEE) e número de grãos por espiga (NGE) obtidos pela média de cinco espigas coletadas, ao acaso, nas quatro linhas centrais de cada parcela; número de espigas por metro (NEM), definido pela contagem das espigas, em duas amostras de um metro linear nas quatro linhas centrais de cada parcela, na fase de enchimento de grãos; massa de mil grãos (MMG), estabelecida por meio da pesagem de mil grãos de cada parcela; e rendimento de grãos (RDG) que foi determinado por meio da colheita e pesagem dos grãos colhidos na área total de cada parcela.

Os dados foram submetidos à análise de variância e os coeficientes de correlação de Pearson entre todas as variáveis foram obtidos pelo método proposto por Steel $\&$ Torrie (1980). Foi realizada a avaliação de multicolinearidade das variáveis pela matriz de correlação genotípica, conforme descrito por Cruz \& Regazzi (1997). Os efeitos diretos e indiretos foram estimados pelo método de análise de trilha ou path analysis, desenvolvido por Wright (1921), considerando o modelo causal, descrito por Cruz \& Regazzi (1997). Para esta última análise, foi utilizada a variável RDG como variável principal e as demais como variáveis explicativas. Todas as análises foram realizadas por meio do programa Genes (CRUZ, 2006).

\section{RESULTADOS E DISCUSSÃO}

A partir do resumo da análise de variância, observa-se que os tratamentos diferiram quanto ao rendimento de grãos (RDG), número de espigas por metro (NEM), número de grãos por espiga (NGE), número de espiguetas por espiga (NEE), tamanho da espiga (TES) e a massa de mil grãos (MMG) pelo “Teste F” ((p<0,05), Tabela 1). Os coeficientes de variação para as variáveis analisadas foram baixos, com valores variando de 4,78 a 9,68\%, mostrando baixa dispersão dos dados segundo a classificação de Gomes \& Garcia, 2002, indicando um comportamento homogêneo dos dados amostrados no experimento.

As estimativas dos coeficientes de correlação genotípica para os caracteres avaliados (Tabela 2) possi- bilitaram verificar ampla magnitude nos valores de correlação genotípica, com valores indicativos variando de 0,781 a 0,945 entre caracteres analisados.

A partir dos coeficientes de correlação, observa-se que as variáveis tamanho de espiga (TES), número de espiguetas por espiga (NEE) e número de grãos por espiga (NGE) apresentaram tendências a associações positivas entre si e com o rendimento de grãos (RDG). As estimativas de correlação genotípica entre estas variáveis, com o rendimento de grãos foram de 0,145, 0,304 e 0,477, respetivamente.

A correlação significativa, porém baixa, observada entre NGE e MMG pode ser explicada pela dificuldade no melhoramento, ou seja, quando se busca um maior número de grãos por espiga tem-se dificuldade em manter o tamanho dos grãos. Segundo Vencovsky \& Barriga (1992), coeficientes de correlação baixos não representam falta de associação entre as características, mas inexistência de causa e efeito.

A análise de multicolinearidade revelou valor reduzido, revelando confiabilidade dos dados utilizados para obtenção dos efeitos diretos e indiretos na análise de trilha Cruz \& Regazzi (1997).

A análise de trilha proporciona um conhecimento detalhado das influências dos caracteres envolvidos em um diagrama previamente estabelecido e justifica a existência de correlações positivas e negativas, de altas e baixas magnitudes entre os caracteres estudados. O desdobramento em efeitos diretos e indiretos dos coeficientes de trilha e de correlação total entre os caracteres em estudo está na Tabela 3.

Na Tabela 3, observa-se correlação total positiva $(0,1449)$, da variável tamanho de espiga (TES) com o rendimento de grãos (RDG), mas seu efeito direto negativo ($3,6601)$ indica ausência de causa e efeito. Nestas condições, é necessário utilizar uma seleção restrita, como sugerida por Vencovsky \& Barriga (1992), a fim de eliminar os efeitos indiretos indesejáveis e aproveitar o efeito direto existente.

Entre os caracteres envolvidos no desdobramento dos coeficientes de trilha, o caráter número de grãos por espiga (NGE) revelou alto efeito direto sobre o rendimento de grãos $(2,0126)$, concordando com o valor do coeficiente de correlação genotípica entre estes caracteres, que foi de 0,3037, permitindo estabelecer a hipótese da verdadeira existência de uma associação entre esses caracteres. $\mathrm{O}$ caráter número de espiguetas por espiga (NEE) também revelou alto efeito direto $(2,2795)$ sobre o rendimento de grãos (RDG) com uma correlação total também elevada de 0,4765 . Isto se deve ao fato de os caracteres número de grãos por espiga (NGE) e número de espiguetas por espiga (NEE) estarem altamente correlacionados. A correlação genotípica observada entre estes dois caracteres foi 
Tabela 1. Valores de F e coeficientes de variação referentes ao tamanho da espiga (TES), número de espiguetas por espiga (NEE), número de grãos por espiga (NGE), número de espigas por metro (NEM), massa de mil grãos (MMG) e rendimento de grãos (RDG)

\begin{tabular}{lcccccc}
\hline \multirow{2}{*}{ Fontes de variação } & \multicolumn{9}{c}{ Variáveis } \\
\cline { 2 - 7 } & TES & NEE & NGE & NEM & MMG & RDG \\
\hline Valores de F & $10,08^{*}$ & $3,16^{*}$ & $5,99^{*}$ & $5,71^{*}$ & $42,16^{*}$ & $5,74^{*}$ \\
Coeficiente de variação $(\%)$ & 6,16 & 7,58 & 9,68 & 6,74 & 4,78 & 9,62 \\
\hline
\end{tabular}

* Significativo a $5 \%$ de probabilidade.

Tabela 2. Coeficientes de correlação genotípica de Pearson para os caracteres tamanho da espiga (TES), número de espiguetas por espiga (NEE), número de grãos por espiga (NGE), número de espigas por metro (NEM), massa de mil grãos (MMG) e rendimento de grãos (RDG)

\begin{tabular}{lclllcc}
\hline Caracteres & TES & NEE & NGE & NEM & MMG & RDG \\
\hline TES & 1,0 & 0,895 & 0,934 & $-0,781$ & 0,372 & 0,145 \\
NEE & & 1,0 & 0,945 & $-0,604$ & 0,055 & 0,477 \\
NGE & & 1,0 & $-0,624$ & 0,058 & 0,304 \\
NEM & & & 1,0 & $-0,691$ & 0,057 \\
MMG & & & & 1,0 & $-0,232$ \\
RDG & & & & & & 1,0 \\
\hline
\end{tabular}

Tabela 3. Estimativa dos coeficientes dos efeitos diretos e indiretos e correlação total entre os caracteres tamanho da espiga (TES), número de espiguetas por espiga (NEE), número de grãos por espiga (NGE), número de espigas por metro (NEM), massa de mil grãos (MMG) e rendimento de grãos (RDG)

\begin{tabular}{|c|c|c|c|}
\hline \multirow{2}{*}{ Caracteres } & \multirow{2}{*}{ Efeito } & \multicolumn{2}{|c|}{ Coeficientes } \\
\hline & & trilha & correlação total \\
\hline \multirow{5}{*}{ TES } & Direto sobre RDG & $-3,6601$ & \multirow{5}{*}{0,1449} \\
\hline & Indireto via NEE & 2,0394 & \\
\hline & Indireto via NGE & 1,8798 & \\
\hline & Indireto via $\mathrm{MMG}$ & 0,5480 & \\
\hline & Indireto via NEM & $-0,6623$ & \\
\hline \multirow{5}{*}{ NEE } & Direto sobre RDG & 2,2795 & \multirow{5}{*}{0,4765} \\
\hline & Indireto via TES & $-3,2747$ & \\
\hline & Indireto via NGE & 1,9019 & \\
\hline & Indireto via $\mathrm{MMG}$ & 0,0818 & \\
\hline & Indireto via NEM & $-0,5119$ & \\
\hline \multirow{5}{*}{ NGE } & Direto sobre RDG & 2,0126 & \multirow{5}{*}{0,3037} \\
\hline & Indireto via TES & $-3,4185$ & \\
\hline & Indireto via NEE & 2,1541 & \\
\hline & Indireto via $\mathrm{MMG}$ & 0,0849 & \\
\hline & Indireto via NEM & $-0,5293$ & \\
\hline \multirow{5}{*}{ NEM } & Direto sobre RDG & 0,8482 & \multirow{5}{*}{0,0573} \\
\hline & Indireto via TES & 2,8578 & \\
\hline & Indireto via NEE & $-1,3757$ & \\
\hline & Indireto via NGE & $-1,2559$ & \\
\hline & Indireto via $\mathrm{MMG}$ & $-1,0172$ & \\
\hline \multirow{7}{*}{ MMG } & Direto sobre RDG & 1,4732 & \multirow{5}{*}{$-0,2319$} \\
\hline & Indireto via TES & $-1,3616$ & \\
\hline & Indireto via NEE & 0,1265 & \\
\hline & Indireto via NGE & 0,1159 & \\
\hline & Indireto via NEM & $-0,5857$ & \\
\hline & Coeficiente de Determinação & 0,8740 & \\
\hline & Efeito da variável Residual & 0,3549 & \\
\hline
\end{tabular}

Rev. Ceres, Viçosa, v. 58, n.3, p. 337-341, mai/jun, 2011 
de 0,945 , ou seja, à medida que se aumenta o número de espiguetas por espiga (NEE) aumenta, quase que na mesma proporção, o número de grãos por espiga (NGE).

O caráter massa de mil grãos (MMG) apresentou alto efeito direto $(1,4732)$ sobre o rendimento de grãos (RDG), afirmando a possibilidade de uso da seleção para o rendimento de grãos (RDG) por meio da massa de mil grãos (MMG) pelos programas de melhoramento, entretanto, a correlação total evidenciou valor negativo $(-0,2319)$ por causa dos efeitos indiretos negativos altos do TES (1,3616) e do NEM $(-0,5857)$, pois os efeitos genéticos estão diretamente relacionados com o ambiente e ainda são de caráter quantitativo, ou seja, baixa herdabilidade. O efeito direto positivo do caráter número de grãos por espiga (NGE) e massa de mil grãos (MMG), sobre o rendimento de grãos encontrados neste estudo, concordam com os resultados obtidos por outros autores (Gondim et al., 2008; Caierão et al., 2001; Vieira et al., 2007).

O caráter número de espigas por metro (NEM) revelou um efeito direto positivo $(0,8482)$ sobre o rendimento de grãos (RDG), embora a correlação total encontrada tenha sido baixa $(0,0573)$, este baixo valor de correlação genotípica entre os caracteres, segundo Vencovsky \& Barriga (1992), indica a inexistência de causa e efeito e não representa falta de associação entre os caracteres.

O coeficiente de determinação encontrado $(0,87)$ indica que $87 \%$ do rendimento de grãos obtido é decorrente dos efeitos das variáveis analisadas. Tal coeficiente fica restrito a esses patamares pela razão de estes caracteres serem quantitativos, com grande número de genes de pouco efeito no caráter, apresentando variância ambiental considerável, reduzindo a sua herdabilidade.

\section{CONCLUSÕES}

Existem diferenças entre os genótipos avaliados, demonstrando presença de variabilidade genética.

A seleção indireta para rendimento de grãos, a partir do número de grãos por espiga, levando em consideração a massa de mil grãos, é a melhor estratégia de seleção de genótipos superiores em trigo.

\section{REFERÊNCIAS}

Almeida AHB (1998) Heterose e correlações em plantas branquícas e normais de jerimum caboclo (Cucurbita maxima Duchesne). Dissertação de Mestrado. Universidade Federal de Viçosa, Viçosa. $95 \mathrm{p}$.

Benin G, Carvalho FIF, Oliveira AC, Marchioro VS, Lorencetti C, Kurek AJ, Silva JAG, Cargnin A \& Simioni D (2003) Estimativas de correlações e coeficientes de trilha como critérios de seleção para rendimento de grãos em aveia. Revista Brasileira de Agrociência, 9:9-16.

Bell GDH (1987) The history of wheat cultivation. In: Lupton FGH. Wheat breeding. Chapman and Hall. p. 31-50.
Benin G, Carvalho FIF, Oliveira AC, Hartwig I, Schmidt D, Vieira EA, Valério EP \& Silva JG (2005) Estimativas de correlações genotípicas e de ambiente em gerações com elevada frequência de heterozigotos. Ciência Rural, 35:523-529.

Carvalho FIF, Lorencetti C, Marchioro VS, Silva AS (2008) Condução de populações no melhoramento genético de plantas. Pelotas. Editora Universitária. Segunda edição. 288p.

Caierão E, Carvalho FIF, Pacheco MT, Lonrecetti C, Marchioro VS, Silva, JG (2001) Seleção indireta em aveia para o incremento no rendimento de grãos. Ciência Rural, 31:231-236.

Chaudaury D (1973) Genetic variability and correlation for yield components in rice. Indian Journal of Agricultural Sciences, 43:181-184.

Comissão Sul Brasileira de Pesquisa de Trigo (2006) Informações técnicas da Comissão Sul-Brasileira de Pesquisa de Trigo e Triticale para a Safra 2006. Passo Fundo, Embrapa CNPT. 159p.

Coodetec (2008) Cooperativa Central de Pesquisa Agrícola. Disponível em: www.coodetec.com.br. Acesso em: 20 de maio de 2008.

Cruz CD (2006) Programa Genes - Estatística Experimental e Matrizes. $1^{\text {a }}$ ed. Viçosa, Editora UFV. 285p.

Cruz CD \& Regazzi AJ (1997) Modelos biométricos aplicados ao melhoramento genético, $2^{\mathrm{a}}$ ed. Viçosa, Editora UFV. 390p.

Feldman M. (1976) Wheats. In: Simmonds NW Evolution of crop plants. London, Longman, p.121-128

Gomes FP, Garcia CH (2002) Estatística aplicada a experimentos agronômicos e florestais. Biblioteca Luiz de Queiroz. 309p

Gondim TCO, Rocha VS, Sediyama CS \& Miranda GV (2008) Análise de trilha para componentes do rendimento e caracteres agronômicos de trigo sob desfolha. Pesquisa Agropecuária Brasileira, 43:487-493.

Marchioro VS, Franco FA, Dalla Nora T, Oliveira EF, Schuster I, Vieira ESN \& Evangelista A (2009) CD 117: nova cultivar de trigo de ampla adaptação. Pesquisa Agropecuária Brasileira, 4:424-426.

Silva AS, Carvalho FIF, Nedel JL, Cruz JC, Silva JAG, Caetano VR, Hartwig I \& Sousa CS (2005) Análise de trilha para os componentes de rendimento de grãos em trigo. Bragantia, 64:191196.

Steel RGD \& Torrier JH (1980) Principles and procedures of statistics. A biometrical approach. $2^{\text {a }}$ ed. New York, McGrawHill. 418p.

Valério I P, Carvalho FIF, Oliveira AC, Machado AA, Benin G, Scheeren PL, Souza VQ \& Hartwig I (2008) Desenvolvimento de afilhos e componentes do rendimento em genótipos de trigo sob diferentes densidades de semeadura. Pesquisa Agropecuária Brasileira, 43:319-326

Vieira EA, Carvalho FIF, Oliveira AC, Martins LF, Benin G, Silva JAG, Coimbra J, Figueirola A, Carvalho MF \& Ribeiro G (2007) Análise de trilha entre os componentes primários e secundários do rendimento de grãos em trigo. Revista Brasileira de Agrociência, 13:169-174.

Vencovsky $\mathrm{R} \&$ Barriga P. Genética biométrica no fitomelhoramento. Ribeirão Preto: Revista Brasileira de Genética, 1992. 496p.

Wright S (1921) Correlation and causation. Journal of Agriculture Research, 20:557-585.

Rev. Ceres, Viçosa, v. 58, n.3, p. 337-341, mai/jun, 2011 